\title{
A IMPORTÂNCIA DA DISCUSSÃO DA MORAL NA EDUCAÇÃO PÚBLICA: ENSAIOS SOBRE AQUISIÇÃO DOS VALORES MORAIS NA SOCIEDADE CONTEMPORÂNEA
}

\section{THE IMPORTANCE OF DISCUSSING MORALS IN PUBLIC EDUCATION: ESSAYS ON THE ACQUISITION OF MORAL VALUES IN CONTEMPORARY SOCIETY}

Marcos Antonio Madeira de Mattos Martins', João Henrique de Oliveira Bento², Karla Cristina da Costa e Silva de Mattos Martins ${ }^{3}$, Alessandro Marco Rosini ${ }^{4}$, Angelo Palmisano ${ }^{5}$, Marcio Magera Conceição ${ }^{6}$

1 Doutor em Direito pela Pontifícia Universidade Católica de São Paulo, PUC-SP; Mestre em Direito da Sociedade da Informação pela FMU - São Paulo. Pós-Graduado (MBA) em Gestão Empresarial pela Fundação Getúlio Vargas - RJ. Pós-Graduado em Direito Civil e Processo Civil pela Escola Superior de Advocacia São Paulo. Professor de Pós-Graduação da Faculdade de Direito de Franca. Membro avaliador do Conselho Nacional de Pesquisa e Pós-Graduação em Direito. Professor de Cursos de Extensão na Escola Superior de Advocacia - SP. Membro do Conselho de Pareceristas da Revista de Direito Econômico e Socioambiental da PUC-PR. Avaliador permanente da Revista de Direito, Governança e Novas Tecnologias. Revisor da Revista de Ensino e Pesquisa em Administração e Engenharia (REPAE), focada na administração pública, de empresas e ciências ambientais. Como gestor jurídico, desenvolve plano de administração de riscos corporativos para implementação de boas práticas de governança, criando políticas de proteção de ativos (asset protection). Investiga, analisa e registra informações coletadas no ambiente interno e no campo externo organizacional para criação de relatório de gestão de riscos (Risk Management Report) possibilitando a integração do compliance com possíveis condutas criminosas dos gestores, diretores, administradores e CEOs de corporações. Como pesquisador e advogado, elabora pareceres técnicos e presta consultoria preventiva e assessoria jurídica contenciosa nas áreas de Criminal Compliance, Governança Corporativa, Gestão do Comportamento Organizacional, Riscos Trabalhistas, Análises Estratégicas, Crise Empresarial e Redesenho Organizacional.

2 Graduado em Filosofia pela Pontifícia Universidade Católica de Campinas - PUC - Campinas. Pós-graduado em Psicopedagogia Institucional. Aluno especial em temas da filosofia e psicologia, na linha da Psicanálise, Unicamp. Iniciação científica em Teologia na Pontifícia Universidade Católica de Campinas, PUC - Campinas. Graduando em Direito pelo Centro Universitário Salesiano de São Paulo, UNISAL Campinas. e-mail: joaohenrique.bento@hotmail.com

3 Mestre em Direito da Sociedade da Informação pela Uni-FMU - São Paulo; Pós-graduada em LLM Direito dos Negócios pelo Centro Universitário das Faculdades Metropolitanas Unidas; Graduada em Direito pelo Centro Universitário das Faculdades Metropolitanas Unidas. Ex-Coordenadora da Escola Superior de Advocacia - SP, núcleo Subseção. Professora de Cursos de Pós-Graduação na Escola Superior de Advocacia - São Paulo. Professora de Direito da Propriedade Intelectual na Faculdade de Direito de Itu. Advogada.

4 Pós-Doutor em Administração de Empresas pela FEAUSP - alessandro.rossini@yahoo.com

5 Doutor em Ciências Sociais (2003); Mestre em Administração (1999); Graduado em Administração de Empresas (1981), todos cursados na Pontifícia Universidade Católica de São Paulo - PUC/SP. Atuou como Pró-Reitor Acadêmico e Pró-Reitor de Pós-Graduação, Pesquisa e Extensão do Complexo Educacional FMU. Coordenou o Programa e atuou como Professor do Mestrado Profissional de Administração em Governança Corporativa do Centro Universitário das Faculdades Metropolitanas Unidas - FMU até outubro de 2015. Possui experiência nas áreas de administração empresarial e educacional, sobretudo como professor e gestor acadêmico no ensino superior (Graduação e Pós-Graduação), ensino à distância, educação continuada, avaliação institucional, gestão do conhecimento, gestão da qualidade, gestão da tecnologia da informação, inovação tecnológica, gestão de pessoas e governança corporativa. É sócio diretor da Pereira e Palmisano Consultoria e Treinamentos nas áreas de gestão empresarial e educação superior. Atua como pesquisador em grupos de pesquisa nas áreas de gestão, estratégia empresarial, qualidade, engenharia, ética, sustentabilidade, responsabilidade social e governança corporativa. Atua em reestruturação acadêmica e administrativa de instituições de ensino superior desde 1997.

6 Pós-doutorando junto a Faculdade Funcional de Ecologia Universidade de Coimbra, Portugal. Projeto em andamento, ano 2018. Pós-Doutor junto ao Departamento de Sociologia do Instituto de Filosofia e Ciências Humanas IFCH da Unicamp, SP, sob orientação do Prof. Dr. Ricardo Luiz C. Antunes, ano 2004 e 2005. Post Doctor in International Relations, do Programa de Estudos de Pós-Graduação Stricto Sensu da Florida Christian University FCU. Memorial de conclusão de curso entregue em novembro de 2013, no Seminário Internacional em Orlando, Florida, USA, 2013. Doutor em Ciências Sociais Sociologia na Pontifícia Universidade Católica de São Paulo - PUC, SP, 2002. Doutor em Administração de Negócios na Florida Cristhian University FCU USA, 2010. Mestre em Ciências Sociais Área de Concentração Sociologia, pela PUC-SP, 2001. Mestre em Administração de Empresas pela Universidade Guarulhos - SP, 1999. MBA de Gestão de Marketing na ESAMC Sorocaba, SP, 2007. Bacharel em Ciências Econômicas - Pontifícia Universidade Católica de Campinas SP, ano 1993. Jornalista MTB 556.03.81V-SP. 


\section{RESUMO}

Este artigo trata do processo de transmissão da moralidade e a aprendizagem dos valores no mundo pós-moderno. A partir do aprofundamento dos conceitos de moralidade, educação e aquisição de moralidade, entende-se que é na interação e relação interpessoal que a moral se forma e se estabelece. O desenvolvimento moral ocorre quando a criança aprende como agir perante o outro, respeitando regras e promovendo a dignidade humana. $\mathrm{O}$ artigo indica um paradoxo da pós-modernidade: o imenso desenvolvimento tecnológico em detrimento de imaturidade política e crise da ética e moral. Por fim, apresenta a teoria construtivista como uma possível solução para resolução do problema de aquisição dos valores morais.

PALAVRAS-CHAVE: Moralidade. Aprendizagem. Valores morais. Pós-modernidade. Construtivismo.

\section{ABSTRACT}

This article deals with the process of transmission of morality and learning values in the postmodern world. From the deepening of concepts of morality, education and acquisition of moral values, it is understood that it is the interaction and interpersonal relationship that morality is formed and established. Moral development occurs when children learn how to act before the other, respecting rules and promoting human dignity. The article points out a paradox of postmodernity: the immense technological development at the expense of political immaturity and crisis of ethics and morals. Finally, it shows the constructivist theory as a possible solution for solving the problem of acquisition of moral values.

KEYWORDS: Morality. Learning. Moral values. Postmodernity. Constructivism. 


\section{INTRODUÇÃO}

Com o intuito de compreender a aprendizagem humana dos valores morais e a importância da educação na consolidação desse processo da transmissão de moralidade, esse artigo visa aprofundar os conceitos e articulá-los com a problemática em questão. Trata-se da aquisição dos valores morais no mundo pós-moderno, marcado pelo esvaziamento dos mesmos valores e pela crise da ética.

Essa reflexão se inicia conceituando os temas que serão abordados, tais como: moral, educação, aprendizagem humana, aquisição de valores morais no mundo pós-moderno, crise da ética, dentre outros. São expostos elementos que colaborarão para compreensão de tais conceitos, tanto de moralidade, como de educação, a partir da obra de Piaget e também de outros importantes teóricos como Paulo Freire.

Na primeira parte do artigo o tema abordado é moral, moralidade e educação, que são fundamentais para a reflexão que se segue. É importante compreender esses conceitos à luz da teoria de Piaget, que é educador principal do presente estudo, mas sem desconsiderar Paulo Freire com suas contundentes reflexões, sobretudo sobre educação.

O segundo momento é intensificado pelo aprofundamento do processo de aquisição de valores morais. Partindo dos resultados das pesquisas realizadas com crianças por Piaget, a reflexão se expande a fim de intensificar a compreensão sobre o desenvolvimento moral e aquisição de valores.

De modo sucinto e rápido, tendo em vista apenas contextualizar a problemática, o terceiro momento do trabalho traz uma caracterização do mundo pósmoderno. Neste trecho utiliza-se tanto de elementos da sociologia como de argumento filosófico. Os dois grandes teóricos aqui indicados são Gilles Lipovetsky e Bauman.

A última parte do artigo, o trecho quarto, tem como pano de fundo a problematização da moralidade no mundo pós-moderno. Não se trata de uma crítica à pós-modernidade em si no sentido filosófico. Significa de modo mais amplo uma reflexão sobre o processo de aprendizagem dos valores a partir da pós-modernidade com suas questões problemáticas, sobretudo as que envolvem os valores morais.
Por fim, após ter entendido os conceitos de moral, moralidade e educação; depois aprofundado o processo de aquisição dos valores morais e por último contextualizado o mundo pós-moderno e alguns de seus empasses, encerra-se refletindo sobre a importância do construtivista no mundo contemporâneo.

\section{COMPREENDENDO MELHOR OS CONCEITOS DE MORAL, EDUCAÇÃO E APRENDIZAGEM}

Primeiramente quando se fala em moral está justamente se referindo a um sistema de regras e sua efetivação no mundo prático, porque segundo Piaget (1994, p.23) "toda moral consiste num sistema de regras, e a essência de toda moralidade deve ser procurada no respeito que o indivíduo adquire por essas regras". A moral é basicamente o bem agir humano, o que determina as escolhas que o ser humano realiza entre fazer ou não uma determinada ação. Por isso, a moral está totalmente ligada ao mundo prático.

É na interação e relação interpessoal que a moral se forma e se estabelece, sendo assim, não há moral sem o outro. O tema da moral impõe não somente uma, mas várias dificuldades de estudo e sistematização. Antes de Piaget Levy-Bruhl já indicava uma das dificuldades: "Não há e nem pode haver moral teórica" (PIAGET,1994, p.23). Ainda de um modo mais enfático: "Uma moral mesmo quando teórica é sempre normativa, e justamente porque é normativa, nunca é realmente teórica" (PIAGET,1994, p.23). Sendo assim, fica evidente que para estudar a moral é preciso observar as regras e a conduta, ou seja, o cumprimento efetivo destas.

Outro conceito importante, a saber, é educação. Trata-se de um conceito muito abrangente e de acordo com Paulo Freire: "Não é possível fazer uma reflexão sobre o que é educação sem refletir sobre o próprio homem"1(FREIRE, 1979, p. 27). É que estes conceitos são inseparáveis, uma vez que educação é uma busca que o homem realiza. Nesse sentido, entendemos por educação um processo inteiramente humano, no qual o homem é sujeito transformador. E esse fator é muito importante para entender a humanidade e seu desenvolvimento ao longo da história.

Educação não significa um mero treinamento,

1 
nem uma instrução, ela está num nível maior, uma vez que envolve desenvolvimento ético e moral, visando à plena formação do cidadão. Lins explicita que a "educação é um processo filosófico de transformação do individuo enquanto pessoa inacabada e necessitada de interferências, mas ao mesmo tempo inserida no meio social" (LINS, 2010, p. 72). O meio social é fundamental no processo educacional, uma vez que é na convivência que se constrói os valores.

É justamente por isso que aprender significa, em termos gerais, um ato de transformação; no qual o ser humano vai se construindo e se formando enquanto tal. Sabendo de suas limitações e necessidade de progresso, ou seja, ao perceber-se inacabado, o homem sente necessidade da educação. Paulo Freire afirma que "a educação é possível para o homem, porque este é inacabado e sabe-se inacabado" (FREIRE, 1979, p.28).

É importante diferenciar educação de aprendizagem. Lins deixa claro que "toda educação envolve aprendizagem, o que acontece no âmbito da instrução, mas nem toda aprendizagem é um ato de educação" (LINS, 2010, p. 72). Aprendizagem e educação andam juntas quando existe vinculação a valores éticos. Em outras palavras, quando a aprendizagem está pautada em princípios éticos e valores morais há educação.

Existem várias definições de aprendizagem e modos distintos de se entender como ela ocorre, mas, em todas as teorias há consenso de que aprendizagem é um processo de transformação do individuo e que a educação tem por finalidade tornar o ser humano meIhor. Desse modo, aprender significa desenvolver-se a ponto de mudar as atitudes. Isso fica bem explicitado por Lins no seguinte trecho: "Todo processo educativo é complexo e reúne uma grande quantidade de elementos que se associam visando uma mesma finalidade que é a formação e aperfeiçoamento contínuo do ser humano" (LINS, 2010, p.70).

Está claro que o tema da moral está vinculado ao mundo prático, das normas e das regras que estabelecem o modo de agir, fundamentado na ação e não em teorias que não possuem correspondência com o real. Isso enaltece a importância de se estabelecer momentos fortes de relações interpessoais e interação para se deparar com a necessidade da moralidade.

\section{A AQUISIÇÃO DE VALORES MORAIS}

Vinculado ao processo educacional está o da aquisição de valores morais, ou o processo de desenvolvimento moral, que ocorre quando a criança aprende como agir perante o outro, respeitando regras e promovendo a dignidade humana. No prefácio da obra de Piaget, Yves de La Taille indica a importância que será dada na relação entre educação e moralidade.

Piaget verificou que o universo moral de cada um é composto de hábitos e tradições impostos pelas gerações passadas. Mas a razão, se desenvolvida, pode contrabalançar estes lastros históricos, submetê-los à crítica, transformá-los, quem sabe aperfeiçoá-los (LA TAILLE, 1994, p. 7).

Fica evidente no trecho supracitado que a educação não só é responsável pela moralidade no sentido de transmissão das regras morais, como é fundamental na formação crítica e racional que permite transformar e aperfeiçoar as regras. Para modificar uma regra ou darIhe novo sentido- é necessária a compreensão plena da regra e sua importância, e depois realizar a ressignificação elaborada diante da necessidade apresentada.

Tais regras são transmitidas às crianças por meio de processos de aprendizagem. Piaget enfatiza que as regras morais são ensinadas pelos adultos e que a crianças aprendem a respeitar. Mas, a problemática apresentada é que tais regras são recebidas pelas crianças totalmente prontas e fechadas; elas provêm de uma sucessão de transmissão através de gerações adultas anteriores, ou, seja, elas não são elaboradas de acordo com as necessidades e o interesse das crianças, simplesmente são lançadas como conteúdo a ser apreendido.

Ora, as regras existem e são necessárias para que haja relações interpessoais mais justas e harmônicas, elas colaboram para o convívio social e também são necessárias ao bem viver. Piaget entende que a importância das regras não está nelas em si, mas no motivo de as estarmos seguindo. Telma Vinha explica isso do seguinte modo: "o valor moral de uma ação não está na mera obediência às regras determinadas socialmente, mas sim no princípio inerente a cada ação" (VINHA, 2008, p. 11239). Sendo, assim é o por- 
quê das regras que deve ser explorado nos processos educacionais, sobretudo na prática e vivência.

Através de uma pesquisa realizada com crianças de até sete anos, Piaget constatou que há um grande respeito pelas regras por parte das crianças. Elas respeitam e seguem as regras sem questioná-las, porque estão numa fase denominada heterônomas. Para elas, as regras são eternas e sua autoridade está ligada a Deus, aos pais e aos administradores da cidade. Elas atribuem tanto valor a essas regras que mesmo se todas as crianças quisessem mudar as regras e concordassem com as novas regras inventadas, isso de nada valeria, ou seja, a verdade e a justiça das regras estão ligadas à tradição, à autoridade.

De acordo com Telma Vinha "o desenvolvimento moral refere-se ao desenvolvimento das crenças, dos valores, das ideias dos sujeitos sobre a noção do certo, do errado, dos juízos" (VINHA, 2008, p.17). É nesse desenvolvimento que se forma na consciência a importância da ação boa em detrimento da ação má, e isso se dá na relação interpessoal. Não é possível chegar a tais conclusões de modo isolado, o ser humano é um ser de relações, é justamente aí que surge a necessidade da moralidade.

Todos os ambientes sociais, tais como família, escola, igreja, dentre outros, são importantes e exercem influência na construção dos valores morais. Existe uma dinâmica de interação entre o indivíduo e o meio, e este sobre ele. Telma Vinha enfatiza: "Será durante a convivência diária, desde pequena, com o adulto, com seus pares, com as situações escolares, com os problemas com os quais se defronta, e também experimentando, agindo, que a criança irá construir seus valores, princípios e normas" (VINHA, 2008, p. 11239).

Segundo Piaget, a criança nasce na anomia, que é a ausência de regras. Este é o período inicial, comum a todos, uma vez que ninguém nasce sabendo das regras de convivência de uma sociedade. Quando a criança atinge certo conhecimento de mundo ela ingressa na era heterônoma, mencionada acima. O grande objetivo da educação no processo de aquisição de valores morais é criar no individuo a autonomia.

A autonomia é o estágio mais importante, porque garante a conduta pautada em princípios éticos e morais que foram internalizados durante o processo de aprendizagem. Telma Vinha afirma que "o indivíduo que é autônomo segue regras morais que emergem dos sentimentos internos que o obrigam a considerar os outros além de si, havendo a reciprocidade" (VINHA, 2008, p.11240). Sendo assim, se houver um processo educacional que consiga realizar adequadamente o desenvolvimento moral das crianças, fazendo -as atingir autonomia, haverá uma sociedade melhor.

\section{CARACTERIZAÇÃO DO MUNDO PÓS-MODERNO}

Muitos são os avanços tecnológicos e científicos do mundo pós-moderno. Depois das grandes revoluções, cientifica e industrial, ocorridas na modernidade, surge uma era voltada para o consumo desenfreado. Trata-se da pós-modernidade, ou o mundo contemporâneo, que vive o paradoxo entre desenvolvimento e crise da ética e moral.

O filósofo Gilles Lipovetsky expressa a abrangência do consumismo no mundo pós-moderno do seguinte modo: "Pouco a pouco, o espírito de consumo conseguiu infiltrar-se até na relação com a família e a religião, com a política e o sindicalismo, com a cultura e o tempo disponível" (LIPOVETSKY, 2007, p. 14). Fica evidente que na pós-modernidade há uma forte instauração do consumismo em todas as dimensões da sociedade.

Consumir se torna o verbo-chave do mundo pósmoderno - é o novo lema das sociedades contemporâneas. O que antes era instrumento para realização das outras atividades humanas, se torna a atividade humana por excelência. Há prazer no consumo, que não é mais um meio, mas um fim em si mesmo.

O espírito consumista afeta sobretudo as crianças e adolescentes que se tornam hiperconsumidores; eles participam ativamente da sociedade consumista e são alvo do mercado, uma vez que o consumo se tornou instrumento de felicidade e prazer. De acordo com Lipovetsky está instaurada "a era da criança hiperconsumidora, escutada, tendo o direito de fazer suas próprias escolhas, dispondo de parcela de poder econômico" (LIPOVETSKY, 2007, p. 120).

Para Lipovetsky, as crianças hiperconsumidoras são responsáveis por grande parte das despesas familiares; elas chegam até a fazer chantagem com os pais para adquirir o direito de consumir. Desse modo, corre-se o risco de surgir uma perigosa ideia de que tudo pode ser comprado. 
As relações interpessoais no mundo pós-moderno são fortemente afetadas pelo espírito do consumismo. Esse fator coloca a ética e a moral em grande crise. Bauman, um grande sociólogo do nosso tempo, alerta para o risco da pós-modernidade: "Resta a ver se o tempo da pós-modernidade passará para a história como crepúsculo ou como renascimento da moralidade" (BAUMAN, 1997, p.8).

\section{A MORALIDADE E A PROBLEMÁTICA DOS VALORES NO MUNDO PÓS-MODERNO}

O mundo pós-moderno apresenta um conjunto de padrões e condutas que determinam o modo de vida das pessoas, interferindo no sujeito. Há grande liquidez nas relações, ou seja, os valores e as normas morais que fundamentam o agir mudam de forma volátil e constante. Diante da falta de princípios de moralidade nas ações do homem pós-moderno nota-se falhas nos processos de aprendizagem atuais.

Estabelecido que sendo animal racional, o homem busca melhorar sua condição de existência; e que a educação é fundamental na transformação da humanidade. Além de querer responder à suas mais inquietantes questões, como: o que sou? De onde venho? Para onde vou? E tantas outras tão angustiantes como estas. De fato, como afirma Cortella, o homem, através da educação, consegue ser "construtor de sentido, porque, fundamentalmente, é construtor de si mesmo, a partir de uma evolução natural" (CORTELLA, 201, p.32).

Em outras palavras, através da educação, o homem constrói um novo mundo, cheio de sentido e melhor para se viver. Basta fazer sobrevoo na história e perceber como o conhecimento ajudou o homem a melhorar sua condição de vida, desde o homem da caverna até os dias atuais, nos quais os prédios chegam aos arranha-céus e o homem se locomove quilômetros em poucas horas. Ele consegue transmitir informações para o outro lado do mundo em segundos, através da internet.

A educação e a aprendizagem fazem parte da transmissão de toda uma experiência vivida pela humanidade nesse percurso evolutivo. Regis de Morais refletindo sobre o viver em sociedade, afirma que:
A educação desponta como uma das mais importantes (reflexões), praticamente atravessando todas as fases da convivência humana, como característica da inteligência acumulativa do homem e de suas crescentemente desenvolvidas habilidades de transmissão do saber e da experiência de vida (MORAIS, 2008, p. 26).

Como explícito no trecho supracitado, a educação transmite um saber acumulado nas experiências humanas. Em outras palavras, o conhecimento é fruto da convivência humana e de sua relação com o mundo. A educação é a ponte que carrega o conhecimento adquirido através das gerações. Isso quer dizer que o simples fato de comer cozido e não cru, por exemplo, é um saber acumulado por gerações.

O mesmo ocorre com a moral. As regras são passadas de gerações em gerações, alicerçadas em princípios universais e trazem a garantia de regular a convivência humana afim de construir uma sociedade justa e respeitosa e promover a dignidade da pessoa humana.

É bem conhecido que em diversos momentos da história várias crises afetaram a vida humana. Entretanto, é fundamental destacar que algumas crises, devido sua complexidade, colocam em questão o fundamento da sociedade ${ }^{2}$. Eis a questão que se apresenta na contemporaneidade: "vivemos um imenso desenvolvimento tecnológico, entretanto uma imaturidade política e social muito grande"3, desproporcionalmente.

Eis o cerne de nossa reflexão: por um lado evoluímos em termos de conhecimento haja vista a tecnologia e outros aspectos do mundo atual. Por outro lado, percebemos uma espécie de retrocesso em muitas outras questões. Não é preciso ir longe para perceber o desrespeito com a natureza, a falta de paciência no trânsito, os problemas de corrupção na política, o analfabetismo político, o aumento da violência, dentre outros aspectos que denotam o problema da crise ética e moral.

Como foi estudado nos trechos anteriores, de acordo com Jean Piaget, o sujeito tem papel funda-

2 MOSÉ, Viviane. Os Desafios contemporâneos: A Educação - por Viviane Mosé (Café Filosófico) - Completo disponível em https://www.youtube.com/watch?v=hRfZLQrAt5A acessado no dia 19 de agosto de 2015.

3 Viviane Mosé cita em seu documentário o Professor Rui Canário 
mentalmente ativo no processo de aquisição de valores morais ${ }^{4}$. Entretanto, não tão somente isso, o meio também tem importância crucial nessa construção valorativa. Sendo assim, há forte relação individuo e contexto e vice e versa. As regras morais existem para garantir a boa convivência em sociedade, seu sentido de ser não está em si, mas em seu objetivo prático. Piaget afirma que a norma em si não é importante, mas o porquê de as seguirmos (PIAGET,1994).

A visão da escola tradicional sempre olhou para os conflitos existentes dentro da escola como negativos. Para resolvê-los, criaram-se sistemas de regras e punições para transgressões das mesmas. Ora, tal atitude não contribui para a formação da autonomia, pelo contrário, mantém os alunos dentro da heteronomia, onde seguem as regras das autoridades com medo das punições e não por entenderem a importância de segui-las. Para reforçar essa ideia, Telma Vinha cita o exemplo dos alunos que brigam na rua depois de saírem da escola, ou por meio das redes sociais.

Por outro lado, existe a visão construtivista que entende os conflitos como oportunidade para inserir os princípios de moralidade na vida das crianças. Para Vinha:

Os educadores que possuem esta concepção compreendem o conflito e sua resolução como partes importantes do currículo tanto quanto os outros conteúdos que devem ser trabalhados e não apenas o vendo como um problema a ser resolvido. (VINHA, 2008, p.11244).

$\mathrm{Na}$ perspectiva construtivista, a convivência e o mundo prático são considerados fundamentais para o processo de aquisição de valores morais. Isso faz todo sentido, uma vez que para Piaget a moral é uma ciência totalmente prática e não teórica. Sendo assim, todas as ocasiões de conflitos e de problemas pessoais e de relacionamentos interpessoais, são oportunidades de aprendizado. Por exemplo, diante de uma situação de mentira convém refletir sobre a importância da verdade, dentre outras situações.

Desse modo, o professor passa de uma posição de ditador, para a posição de mediador que auxilia não tão somente no processo de conhecimento, mas também de autoconhecimento. Ele ajuda no amadurecimento dos alunos, para que se tornem sujeitos autônomos, capazes de refletir sobre suas atitudes e tomar decisões a partir de valores éticos e morais internalizados durante o processo de aprendizagem. $\mathrm{O}$ construtivista apresenta a vida como a grande escola de ética e moral, todos os momentos são importantes para aprender.

Esses aspectos do construtivista trazem à tona a importância de criar um ambiente escolar que consiga favorecer a vivência dos valores morais. Em outras palavras, um ambiente de construção de moralidade. Vinha explicita:

Sabendo da importância de vivenciar a moral, mas de refletir, discutir e analisar as atitudes, além de trabalhar conteúdos éticos de forma transversal e por projetos interdisciplinares, fazse também necessário que os alunos (e adultos) tenham experiências vividas efetivamente com os valores morais, propiciando uma atmosfera sociomoral cooperativa no contexto educativo. $\mathrm{E}$, é preciso, ainda, oferecer sistematicamente oportunidades para a construção de valores morais aconteça (VINHA, 2008, p. 11247).

Essas questões fazem perceber que os problemas da pós-modernidade podem ser convertidos em oportunidades de reflexão, de aprendizado e de mudança de atitude. A vida é o palco dos acontecimentos das experiências humanas. São nas situações concretas do dia a dia que os valores morais fazem sentido e a ética é vivida intensamente. É preciso investir nas relações humanas, na ação solidária, no contato com o real para construir um mundo mais justo e fraterno. A teoria construtivista se apresenta como uma possível solução para o paradoxo da pós-modernidade.

\section{CONSIDERAÇÕES FINAIS}

O grande objetivo desse artigo era perceber a importância da aprendizagem humana, dos valores e o impacto da educação na humanidade, nas relações e no mundo como um todo. Além disso, entender melhor a crise da ética e da moral no mundo pós-moderno e sua relação com a educação. Ficou claro no trabalho 


\section{revista educação}

que moral é basicamente o bem agir humano, o que determina as escolhas que o ser humano realiza entre fazer ou não uma determinada ação.

Também foi explicitado que a aquisição de valores morais, ou o processo de desenvolvimento moral, ocorre quando a criança aprende como agir perante o outro, respeitando regras e promovendo a dignidade humana. Isso acontece de modo pleno na interação do individuo com o meio e vice-versa num processo dinâmico. O meio social é fundamental no processo educacional, uma vez que é na convivência que se constrói os valores.

Diante da pós-modernidade, ou o mundo con-
A IMPORTÂNCIA DA DISCUSSÃO DA MORAL NA EDUCAÇÃO PÚBLICA: ENSAIOS SOBRE AQUISIÇÃO DOS VALORES MORAIS NA SOCIEDADE CONTEMPORÂNEA Marcos Antonio Madeira de Mattos Martins ${ }^{1}$, João Henrique de Oliveira Bento ${ }^{2}$, Karla Cristina da Costa e Silva de Mattos Martins ${ }^{3}$, Alessandro Marco Rosini ${ }^{4}$

Angelo Palmisano ${ }^{5}$, Marcio Magera Conceição

temporâneo, que vive o paradoxo entre desenvolvimento e crise da ética e moral, a perspectiva construtivista parece solucionar o problema em questão. Primeiro porque entende que a convivência e o mundo prático são considerados fundamentais para o processo de aquisição de valores morais. Depois por compreender que os problemas da pós-modernidade podem ser convertidos em oportunidades de reflexão, de aprendizado e de mudança de atitude. De modo enfático porque a teoria construtivista apresenta a vida como a grande escola de ética e moral, todos os momentos são importantes para aprender.

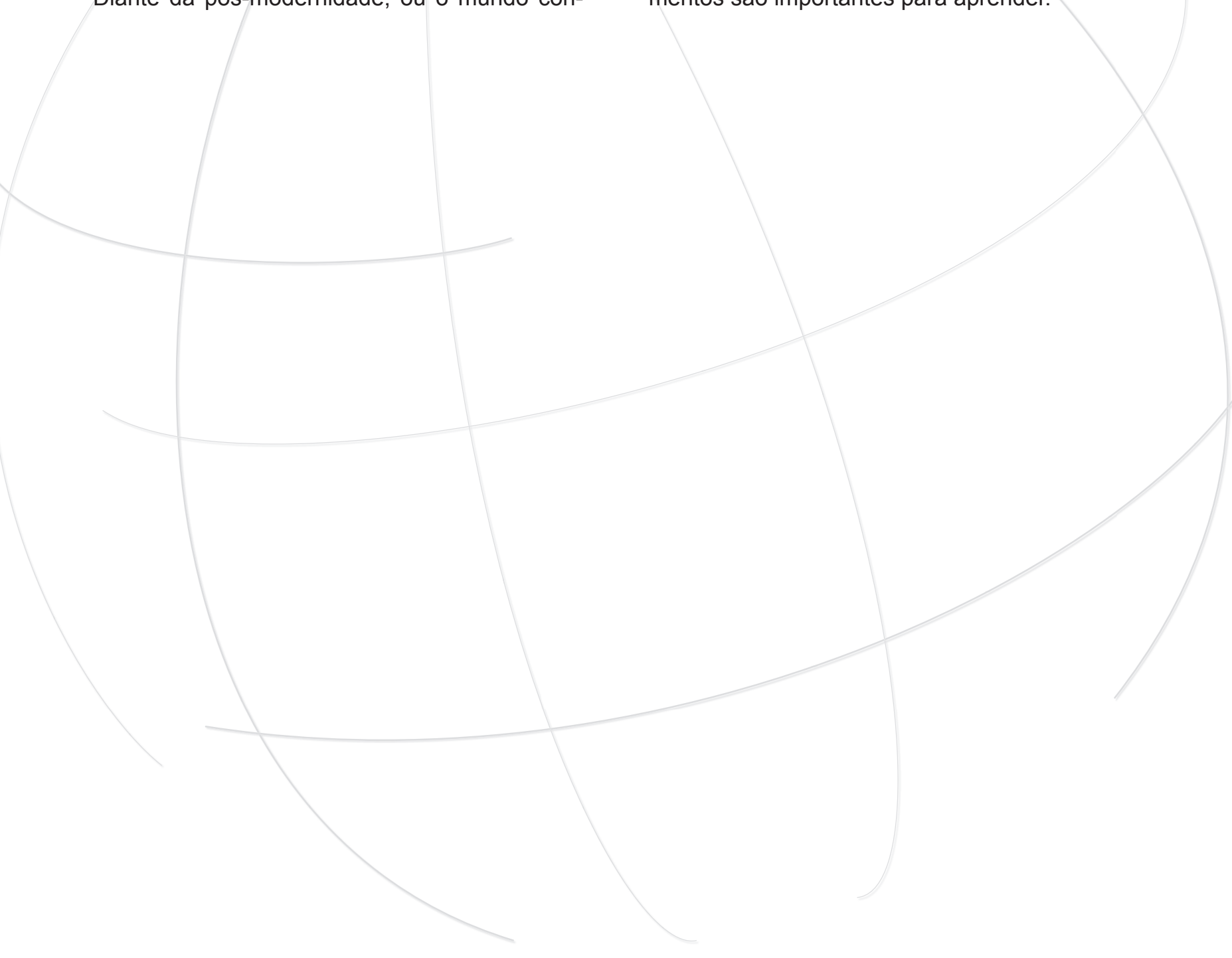




\section{REFERÊNCIAS}

BAUMAN, Zygmunt. Ética pós-moderna. São Paulo: Paulus, 1997. In: BENEDETTI, Luiz Roberto. Religião: crer ou consumir? Revista Vida Pastoral, jul./ago. 2000.

CORTELLA, Mario Sérgio. A escola e o conhecimento: fundamentos epistemológicos e políticos. 14. ed. São Paulo: Cortez, 2011.

FREIRE, Paulo. Educação e mudança. 12 ed. Rio de Janeiro: Paz e Terra, 1979.

LINS, Maria Judith S. da C. Desenvolvimento ético de crianças e psicopedagogia. Rio de Janeiro: UFRJ, 2010.

LIPOVETSKY, Gilles. A Felicidade paradoxal: ensaio sobre a sociedade de hiperconsumo. Trad. Maria Lucia Machado. São Paulo: Companhia das Letras, 2007.

MORAIS, Regis de. Sociedade e educação: estudos sociológicos e interdisciplinares. Campinas: Editora Alínea, 2008.
MOSE, Viviane. Os desafios contemporâneos: a educação - por Viviane Mosé (Café Filosófico). Disponível em: <https://www.youtube.com/watch?v=hRfZLQrAt5A>. Acesso em: 19 ago. 2015.

PIAGET, Jean. O juízo moral na criança. Trad. Elzon Lenardon. São Paulo: Summus, 1994.

VINHA, Telma P. A construção da autonomia moral na escola: a intervenção nos conflitos interpessoais e a aprendizagem dos valores. Campinas: UNICAMP, 2008. Disponível em: http://www.pucpr.br/eventos/educere/educere2008/anais/pdf/295_902.pdf. Acesso em: 20 ago. 2015.

VINHA, T. P. O educador e a moralidade infantil numa visão construtivista. Campinas: Mercado das Letras, 2000. 